\section{Nongonococcal cervicitis: The most common cause of fluor albus in female sex workers}

\author{
Afif Nurul Hidayati, Astindari, \\ Maylita Sari, Dwi Murtiastutik, \\ Sunarko Martodihardjo, \\ Jusuf Barakbah \\ Department of Dermatology and \\ Venereaology, Faculty of Medicine, \\ Universitas Airlangga/Dr. Soetomo \\ General Hospital/Universitas Airlangga \\ Hospital, Surabaya, Indonesia
}

\begin{abstract}
Female sex workers have a high risk of suffering from sexual transmitted infections (STIs). If the female sex workers suffer from STIs, besides affecting themselves, they also have potential to transmit the disease to their clients. Fluor albus is one of the symptoms of STIs. The purpose of this research is to evaluate the type of STIs that the female sex workers suffer from. This research was conducted retrospectively on 100 female sex workers in Puskesmas Putat Surabaya in 2013-2014. The result of this research showed that from 100 female sex workers, 14 subjects (14\%) suffered from gonococcal cervicitis, 51 subjects $(51 \%)$ suffered from nongonococcal cervicitis, 10 subjects $(10 \%)$ suffered from nongonococcal cervicitis accompanied by bacterial vaginosis, 9 subjects (9\%) suffered from bacterial vaginosis, 1 subject ( $1 \%$ ) suffered from trichomoniasis, and 14 subjects $(14 \%)$ had no data. This research concluded that nongonococcal cervicitis is the most major cause of STIs suffered by female sex workers. Therefore, the vigilances to prevent transmission of nongonococcal infection to the clients is highly needed.
\end{abstract}

\section{Introduction}

Sexual transmitted infections (STIs) present a significant major health problem especially in developing countries, since STIs also play a big role in the transmission of Human immunodeficiency virus (HIV). HIV leads to the increase of STIs surveillance importancy. The increase of STIs cases are often accompanied by an increase in HIV cases especially in high-risk subpopulations. ${ }^{1}$ Female sex workers are part of subpopulation that is susceptible towards the transmission of STIs. Clinical manifestation of STI in the form of cervicitis is a cervical inflammatory syndrome that is often seen in infection cases caused by Neisseria gonorrhoeae or Chlamydia trachomatis. The main complaint is vaginal discharge (fluor albus) or bleeding within menstrual period, although cervicitis may also be asymptomatic. ${ }^{2}$ Laboratory infrastructures in majority region in Indonesia are still not optimal, so the data of STIs in various regions are largely based on syndrome approach. Thus far, there has been no research of STIs prevalence in female sex worker subpopulations represented in Surabaya. The purpose of this study is to obtain the description of STIs prevalence in the form of gonococcal and nongonococcal cervicitis, bacterial vaginosis, and trichomoniasis in female sex workers.

\section{Materials and Methods}

This is a retrospective study conducted by collecting data from 100 female sex workers who visited Puskesmas Putat Jaya, Surabaya, Indonesia in 2013-2014. The data were collected from clinical examination, diagnosis, and treatment given. The diagnosis of fluor albus is based on anamnesis, physical examination, vaginal and cervix smears. The data were tabulated and analysed descriptively afterwards.

\section{Results}

The result of the clinical examinations showed that there were 85 subjects $(85 \%)$ suffered from fluor albus, and 1 subject $(1 \%)$ suffered from genital vegetation. Unfortunately, 14 subjects (14\%) had no data (Figure 1). The most etiology of fluor albus was nongonococcal cervicitis in 51 subjects $(51 \%)$, while gonococcal cervicitis occurred in 14 subjects $(14 \%), 10$ subjects $(10 \%)$ suffered from nongonococcal cervicitis accompanied by bacterial vaginosis, 9 subjects (9\%) suffered from bacterial vaginosis, 1 subject (1\%) suffered from trichomoniasis, 1 person $(1 \%)$ whom suffered from genital vegetation (condyloma acuminate), and 14 subjects (14\%) without information. Treatments were given according to the diagnosis, as shown in Table 1. The duration of being a female sex worker in this study was found that majority $(52 \%)$ as long as $1-5$ years, $31 \%$ more than 5 years and $17 \%$ less than 1 year (Figure 2).

\section{Discussion}

Based on the results of this study, the most frequent complaint and clinical manifestation of STIs in female sex worker in Puskesmas Putat Jaya, Surabaya was fluor
Correspondence: Afif Nurul Hidayati, Department of Dermatology and Venereaology, Faculty of Medicine, Universitas Airlangga/Dr. Soetomo General Hospital/Universitas Airlangga Hospital. Jalan Mayjen Prof. Dr. Moestopo 47, Surabaya, Indonesia

Tel.: +628123028024; Fax: +62318288213.

E-mail: afif_nurulhidayati@fk.unair.ac.id

Key words: Nongonococcal Cervicitis, Fluor Albus, female sex worker

Contributions: the authors contributed equally.

Conflict of interest: the authors declare no potential conflict of interest.

Funding: none.

Received for publication: 1 February 2019 Accepted for publication: 13 February 2019

This work is licensed under a Creative Commons Attribution-NonCommercial 4.0 International License (CC BY-NC 4.0).

CCopyright A.N. Hidayati et al., 2019

Licensee PAGEPress, Italy

Dermatology Reports 2019; 11(s1):8050

doi:10.4081/dr.2019.8050

albus (85\%), although there was no data found about its amount, colour, odor, and consistency. The manifestation of fluor albus is indeed often seen in cervicitis, although some could be asymptomatic. This is in accordance with a study conducted by Pollet and colleagues on 467 female sex workers in Peru, that mentioned most of female sex workers diagnosed with cervicitis had clinical manifestation of fluor albus. ${ }^{2}$ Study that was conducted by Nguyen and colleagues on 405 female sex workers in Vietnam also found $86 \%$ subjects had fluor albus. ${ }^{3}$ Other studies have suggested that fluor albus is actually a weak predictor of STIs detection, since $87,7 \%$ of STIs cases are not accompanied by fluor albus. The presence of fluor albus for STIs screening has a sensitivity score of $12,3 \%$, specificity score of $93,8 \%$, positive predictive value of $34,3 \%$, and negative predictive value of $80,2 \%$. Therefore, STIs treatment based on syndrome approach that is only given to patients with fluor albus should still be confirmed with laboratory test on patients without such complaint, as some STIs may also be asymptomatic.

Vaginal discharge (fluor albus) is the common symptom of female genital tract. It can be caused either by physiologically or phatologically. The difference between physiological discharge and phatological discharge becomes a challenge for practi- 
tioners. Vaginal discharge is often caused by hormonal changes, psychological factors, and noninfectious causes, while pathological vaginal discharge is caused by infection of the vagina or/and cervix. Pathological vaginal discharge of the vagina can be caused by bacterial vaginosis,. Candida sp, and Trichomonas vaginalis. Pathological vaginal discharge of the cervix is often caused by Neisseria gonorrhoeae, Chlamydia trachomatis, and Mycoplasma genitalium. The vaginal discharge caused by Candida sp. is not STI because Candida is considered as a normal flora of genitalia. ${ }^{3}$

The average duration of female sex worker in this study was found to be 1-5 years (Table 1). It was also found in clinical survey in Cotonou in 2014-2015. The average duration of commercial sex worker was 58,7 months. ${ }^{4}$ Nongonococcal cervicitis is the most common STI found (51\%), whereas other STIs were gonococcal cervicitis (14\%), nongonococcal cervicitis accompanied bacterial vaginosis $(10 \%)$, bacterial vaginosis $(9 \%)$, trichomoniasis $(1 \%)$, and condyloma acuminata (1\%). This is in accordance with a study by Pollet and colleagues that found nongonococcal cervicitis as the most common STI compared with other STIs. ${ }^{2}$ Study by Nguyen and colleagues in Vietnam found the prevalence of gonococcal and nongonococcal cervicitis was $54,9 \%$ consisted of $14,9 \%$ of gonococcal cervicitis and $48,4 \%$ of cervicitis caused by Chlamydia trachomatis infection. The high prevalence of cervicitis in the study was found in female sex workers in younger age group. The risk may be due to higher activity, more partners, poor knowledge to prevent STIs transmission, including the negotiation of condom use. ${ }^{5}$ Promotion of $100 \%$ condom use was also done in Putat Puskemas area to decrease STIs prevalence and to prevent STIs and HIV transmission, although the prevalence of STIs is still high in high-risk subjects. It shows the importance of behavioral, cultural, and physiological barrier to the subject. The non-compliance of female sex workers towards condom use to both clients and other sexual partners (non-clients), condom breakdowm factor during sex, and other STIs transmitted through condoms are some factors that may affect the incidence of STIs with cervicitis in female sex workers. ${ }^{4}$ This study has less recording data of baseline data, frequency of intercourse, and condom use, so the connection between cervicitis and these things can not be analysed yet.

The algorithm of vaginal discharge (fluor albus) in vagina should focus on the management of vaginal infections. It differs in high-risk women, such as female sex workers, through the syndrome approach as an indicator of infection in the cervix

\section{STIs in 100 Female Sex Worker}

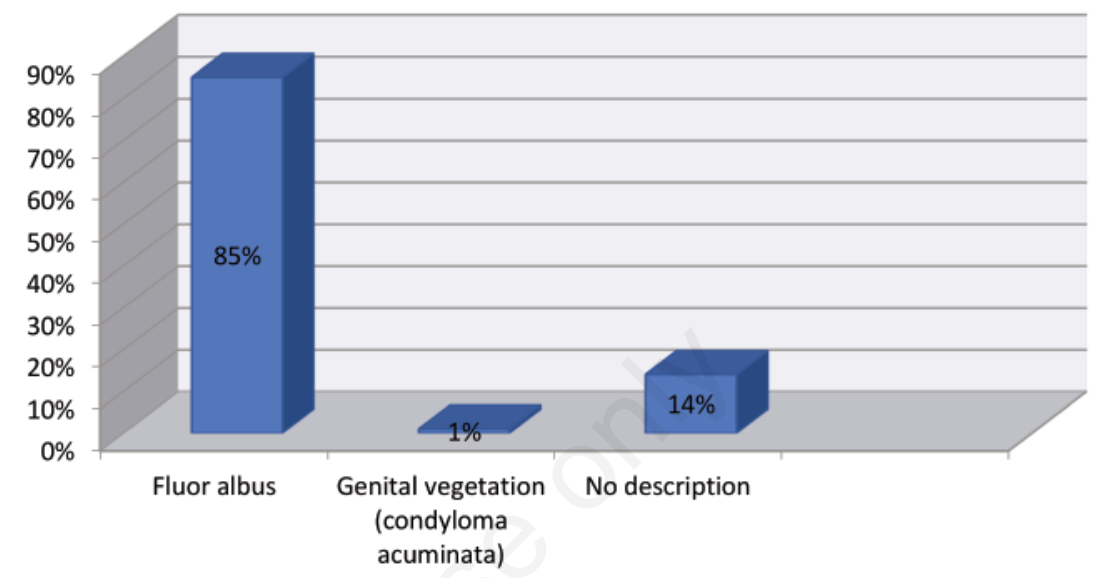

Figure 1. Clinical manifestation of STIs in 100 female sex workers in Puskesmas Putat Jaya, Surabaya in 2013-2014.

\section{The Duration of being Female Sexual Worker}

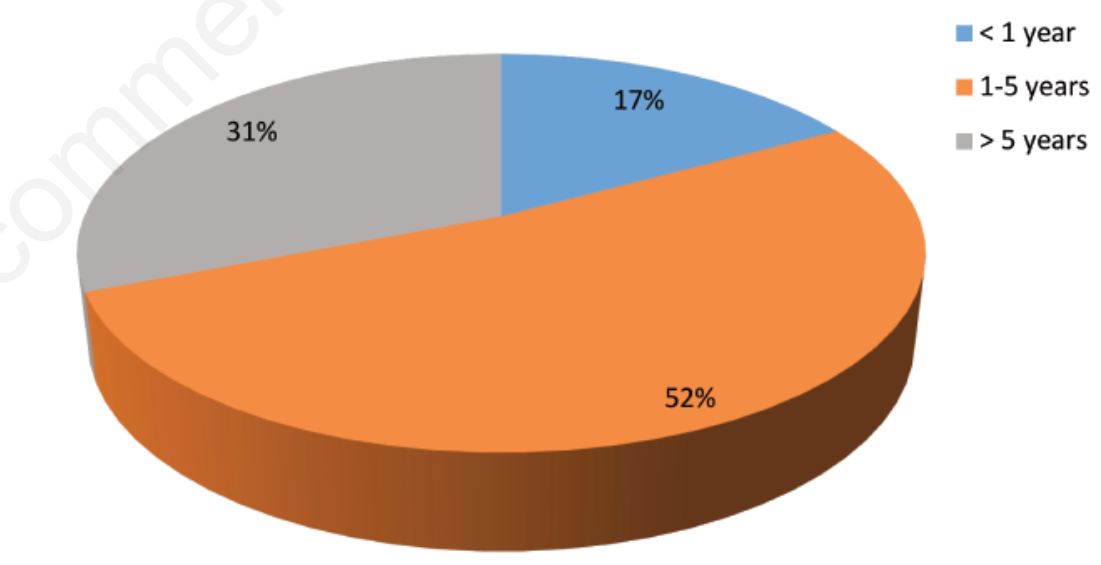

Figure 2. The duration of being a female sex worker of 100 female sex worker in Puskesmas Putat Jaya, Surabaya in 2013-2014.

Table 1. Diagnosis and treatment of STIs in 100 female sex workers in Puskesmas Putat Jaya, Surabaya in 2013-2014.

\begin{tabular}{llll} 
No & Diagnosis & $n=100(\%)$ & Treatment \\
1 & Gonococcal cervicitis & $14(14 \%)$ & Cefixime 400 mg orally single dose + azithromycin $1 \mathrm{~g}$ orally single dose \\
2 & Nongonococcal cervicitis & $51(51 \%)$ & Cefixime $400 \mathrm{mg}$ orally single dose + Azithromycin $1 \mathrm{~g}$ orally single dose \\
\hline 3 & Nongonococcal cervicitis + bacterial vaginosis & $10(10 \%)$ & Cefixime $400 \mathrm{mg}$ orally single dose + Azithromycin $1 \mathrm{~g}$ orally single dose + Metronidazole $2 \mathrm{~g}$ orally single dose \\
4 & Bacterial vaginosis & $9(9 \%)$ & Metronidazole 2 g orally single dose \\
\hline 5 & Trichomoniasis & $1(1 \%)$ & Metronidazole 2 g orally single dose \\
6 & Genital vegetation (Condyloma acuminate) & $1(1 \%)$ & Podophyllin tincture $10 \%$ \\
\hline 7 & Without information & $14(14 \%)$ & Without information \\
\hline
\end{tabular}


because the prevalence of Neisseria gonorrhoeae and Chlamydia trachomatis in highrisk population is higher than low-risk population. $^{3}$

Cervicitis is also more common in female sex workers in the sex business for 12 months because it can be affected by susceptibility factor and lack of susceptible immunity to one of pathogenic causes of cervicitis, i.e. Chlamydia trachomatis. This is demonstrated through a research in Nigeria by Odigie and colleagues in 20142015 , namely the prevalence of acute cervicitis in female sex workers and Chlamydia trachomatis is found to be the most common cause. ${ }^{6}$

Treatment given for gonococcal and nongonococcal cervicitis was cefixime 400 mg orally single dose and azithromycin $1 \mathrm{~g}$ orally single dose, whereas bacterial vaginosis and trichomoniasis were treated with metronidazole $2 \mathrm{~g}$ orally single dose. It referred to program that was run at Puskesmas Putat Jaya to reduce the prevalence of gonococcal and nongonococcal cervicitis/nonspecific genital infection, and other STIs with presumptive treatment. Presumptive treatment is one-time therapy given for infection suspected to occur in a person of group of subjects at high risk of being infected with the disease. Presumptive treatment given regularly at certain period intervals is known as periodic presumptive treatment (PPT). ${ }^{7}$ The program was run at Puskesmas Putat Jaya by providing dual therapy of cefixime $400 \mathrm{mg}$ orally single dose combined with azithromycin $1 \mathrm{~g}$ orally single dose in the case of gonococcal and nongonococcal cervicitis/nonspecific genital infection for female sex workers who come to get routine check at VCT clinic Putat Jaya Puskesmas. Moreover, for female sex workers without complaint or certain STI diagnosis, routinely, with 1-3 months interval, the therapy was also given according to PPT program that was implemented.

\section{Conclusions}

Clinical complaint and manifestation of fluor albus were occured in majority of STIs cases in this study. Nongonococcal cervicitis/nonspecific genital infection was the most common cause of fluor albus. Sign of vaginal discharge/fluor albus in high-risk women may be a marker of cervicitis occurrence caused by Neisseria gonorrhoeae and Chlamydia trachomatis. The syndrome approach could be a strategy to reduce the risk of transmission. Program that was implemented in Putat jaya Puskesmas by providing dual therapy of cefixime $400 \mathrm{mg}$ orally single dose combined with azithromycin $1 \mathrm{~g}$ orally single dose in the case of gonococcal and nongonococcal cervicitis/nonspecific genital infection for female sex workers who come to get routine check at VCT clinic Putat Jaya Puskesmas and promotion of $100 \%$ condom use was an attempt to reduce the prevalence of STIs and to prevent the transmission of STIs and HIV.

\section{References}

1. Mlisana K, Naicker N, Werner L, et al. Symptomatic vaginal discharge is a poor predictor of sexually transmitted infections and genital tract inflammation in high-risk women in South Africa. J Infect Dis 2012;206(1);6-14.

2. Pollett S, Calderon M, Heitzinger K, et al. Prevalence and predictors of cervicitis in female sex workers in Peru: an observational study. BMC Infect Dis 2013;13:195-202.

3. Zemouri C, Wi TE, Kiarie J, et al. The performance vaginal discharge syndromic management in treating vaginal and cervical infection: A systematic review and meta-analysis. PloS ONE 2016;11(10):1-21.

4. Degboe B, Atadokpede F, Adégbidi H, et al. Sexually transmitted infections among sex workers and their clients in Cotonou (Benin) in 2015: Prevalence and risk factors. Clin Dermatol Res J 2017; 2:1.

5. Nguyen VT, Van Khuu N, Thi Le TT, et al. Sexually transmitted infections and risk factors for gonorrhea and chlamydia in female sex workers in Soc Trang, Vietnam. Sex Transm Dis. 2008;35(11): 935-40.

6. Efosa OB, Uwadiegwu AP. Cytopathological examination and epidemiological study of cervicitis in commercial sex workers (CSWs) in Coal City (Enugu), Nigeria. Ethiop J Health Sci 2015;25(3):225-30.

7. World Health Organization. Periodic presumptive treatment for sexually transmitted infection: Experience from the field and recommendation for research. Geneva; WHO; 2008. pp.1-5. 